\title{
Distinct Types of Feeding Related Neurons in Mouse Hypothalamus
}

\author{
Yan Tang ${ }^{1,2}$, Diego Benusiglio ${ }^{2}$, Valery Grinevich ${ }^{2}$ and Longnian Lin ${ }^{1 *}$ \\ ${ }^{1}$ Key Laboratory of Brain Functional Genomics (Ministry of Education and Shanghai), School of Life Science and the \\ Collaborative Innovation Center for Brain Science, Institute of Brain Functional Genomics, East China Normal University, \\ Shanghai, China, ${ }^{2}$ Schaller Research Group on Neuropeptides at German Cancer Research Center, Central Institute of \\ Mental Health, and Cell Networks Cluster of Excellence at the University of Heidelberg, Heidelberg, Germany
}

\section{OPEN ACCESS}

Edited by:

Allan V. Kalueff,

ZENEREI Institute, USA;

GuangdongOcean University, China; St. Petersburg State University, Russia

Reviewed by:

Matthew O. Parker University of Portsmouth, UK

Liangyou Rui,

The University of Michigan, USA

*Correspondence:

Longnian Lin

Inlin@brain.ecnu.edu.cn

Received: 29 February 2016 Accepted: 28 April 2016 Published: 18 May 2016

Citation: Tang Y, Benusiglio D, Grinevich V and Lin L (2016) Distinct Types of Feeding

Related Neurons in Mouse Hypothalamus.

Front. Behav. Neurosci. 10:91. doi: 10.3389/fnbeh.2016.00091
The last two decades of research provided evidence for a substantial heterogeneity among feeding-related neurons (FRNs) in the hypothalamus. However, it remains unclear how FRNs differ in their firing patterns during food intake. Here, we investigated the relationship between the activity of neurons in mouse hypothalamus and their feeding behavior. Using tetrode-based in vivo recording technique, we identified various firing patterns of hypothalamic FRNs, which, after the initiation of food intake, can be sorted into four types: sharp increase (type I), slow increase (type II), sharp decrease (type III), and sustained decrease (type IV) of firing rates. The feeding-related firing response of FRNs was rigidly related to the duration of food intake and, to a less extent, associated with the type of food. The majority of these FRNs responded to glucose and leptin and exhibited electrophysiological characteristics of putative GABAergic neurons. In conclusion, our study demonstrated the diversity of neurons in the complex hypothalamic network coordinating food intake.

Keywords: hypothalamus, feeding-related neurons, firing patterns, feeding behavior, food intake, in vivo recording

\section{INTRODUCTION}

Neural coding of feeding behavior remained unknown for more than half a century due to technical difficulties in accessing deep hypothalamic structures for precise in vivo recording. Another obstacle is the heterogeneity and cross-modal signals of hypothalamic cells, which make it difficult to link cellular activity to specific behavior stimuli. Early studies revealed the lateral hypothalamus (LH) as the hunger center, because its lesion caused hypophagia (Anand and Brobeck, 1951; Grossman et al., 1978). In contrast, the electrical stimulation of LH induced hyperphagia (Hoebel and Teitelbaum, 1962; Margules and Olds, 1962). Later, it was shown that LH neurons respond to food intake (Hoebel and Teitelbaum, 1962; Schwartzbaum, 1988). Early studies employing in vivo recording showed that LH neurons encode sensory stimuli (Norgren, 1970; Yamamoto et al., 1989), including reward-associated cues (Nakamura et al., 1987). LH neurons also fire during both feeding (Burton et al., 1976; Schwartzbaum, 1988) and drinking (Tabuchi et al., 2002), as well as encode circadian rhythm (Ono et al., 1981), respond to odors (Shiraishi, 1988) and taste of glucose (Nakamura et al., 1989; de Araujo et al., 2006). However, due to limitations of the extracellular recording technique, none of these studies identified the chemical nature of feeding related neurons in the LH. Because many neuronal subpopulations co-exist in the LH, it is necessary to combine pharmacological and electrophysiological characteristics to link types of neural response with cell type in the LH. 
The majority of LH neurons affecting feeding behavior are peptidergic in nature. There are three main neuropeptides in the $\mathrm{LH}$, orexin/hypocretin (ORX/hcrt), melanin-concentrating hormone $(\mathrm{MCH})$, and neurotensin (NT), which co-expressed with classical neurotransmitters in individual neurons to specifically modulate feeding behavior. ORX/hcrt neurons contain glutamate (Rosin et al., 2003; Torrealba et al., 2003), central administration of ORX/hcrt acutely promotes feeding (Sakurai et al., 1998) and their activity strongly correlates with finding novel food and its consumption (Mileykovskiy et al., 2005). ORX/hcrt neurons are activated in anticipation of feeding, couple arousal and feeding behaviors (Akiyama et al., 2004; Mieda et al., 2004). Interestingly, ORX promotes feeding during the day but not during dark phases (Haynes et al., 1999; Yamanaka et al., 1999; McGregor et al., 2011), indicating that ORX promotes feeding via an increase of arousal. In contrast to $\mathrm{ORX} /$ hcrt neurons, $\mathrm{MCH}$ neurons are GABAergic and $\mathrm{MCH}$ only amplifies consumption (e.g., size and amount; Baird et al., 2006, 2008), suggesting that MCH regulates general consumption behavior, but not necessarily hedonic aspects of feeding (Clegg et al., 2002; Sakamaki et al., 2005). Furthermore, MCH neurons also coordinate energy expenditure and metabolism (Rossi et al., 1997; Shimada et al., 1998; Marsh et al., 2002) and are able to sense nutrient status, such as glucose levels, and thus enhance the motivation to feed (Kong et al., 2010). The third neuropeptide, NT, is less studied. Several reports demonstrate that NT can coexpress GABA or glutamate (Leinninger et al., 2011; Kempadoo et al., 2013). Its central infusion modestly decreases food intake in satiated and food-deprived rodents (Stanley et al., 1983; Vaughn et al., 1990; Boules et al., 2000) and promotes reward responding (Kempadoo et al., 2013) possible through inhibition of ORX/hcrt neurons (Goforth et al., 2014).

Activity of LH peptidergic neurons is largely dependent on nutritional and hormonal signals: glucose inhibits ORX/hcrt neurons (Muroya et al., 2001; Yamanaka et al., 2003), but excites MCH neurons (Burdakov et al., 2005), while leptin inhibits both types of cells (Goforth et al., 2014; Sheng et al., 2014). As for NT neurons, leptin activates them (Leinninger et al., 2011), although the effect of glucose was not studied in this neuronal type.

Despite accumulated knowledge of the LH neuronal types and circuits involved in food intake, the correlation of the in vivo activity of LH cells with actual feeding behavior is poorly studied. Importantly, the precise structure of firing patterns and neural dynamics of such feeding related neurons (FRNs) in behaving animals remains largely elusive. Using tetrode-based recording techniques, we report here the existence of four distinct types of hypothalamic neurons, which exhibit specific firing patterns directly related to the feeding behavior of freely moving mice.

\section{MATERIALS AND METHODS}

\section{Behavioral Protocols Experimental Animals}

Twenty C57BL/6J male mice (3-8 months old) were used in the experiment. The animals were adapted in the animal facility after delivery from (shanghai SLAC laboratory animal co. ltd) for 4 weeks in a standard day/night cycle $(12: 12 \mathrm{~h})$ room. Then the animals were relocated in separated plastic barrel homecages (55 $\mathrm{cm}$ in diameter, $42 \mathrm{~cm}$ in height; with nest/food/water), and were handled $5 \mathrm{~min}$ per day for a week. The animals were then implanted with chronic electrodes for in vivo recording. After recovery from the surgery, the animals were put into a dim recording chamber for $30 \mathrm{~min}$ per day, allowing them to get used to the recording environment and to find the clear signal of neurons via propelling electrodes gradually into the target area (1-4 weeks). After recording (usually over the course of several months), animals were sacrificed by overdose of isoflurane and transcardially perfused with $4 \%$ paraformaldehyde ( $\mathrm{pH}$ 7.4). Brains were extracted and sectioned (thickness is 40 $\mu \mathrm{m})$ followed by Nissl staining for verification of electrode placement in the hypothalamus. Miss-targeted animals were excluded from the analysis. All mouse work described in this study have been conducted according to Animals Act, 2006 (China) and approved by the Institutional Animal Care and Use Committee (IACUC approval ID \#AR201404006) of the East China Normal University.

\section{Recording Sections Include Pre-Test, Test, and Post-Test}

In all of the feeding related tests, the implanted mice were fasted for $24 \mathrm{~h}$ in homecages before feeding tests started and then they were placed in the recording chamber to get ready to record. All of the recordings were split into three sessions: (1) $30 \mathrm{~min}$ recording as pre-test baseline control, mouse can freely explore in the recording chamber; (2) 30 min recording during the feeding tests, mouse can approach the food and eat freely; during feeding tests the food was delivered automatically at a rate of 3-9 min per pellet, depending on the food amount (25, 50, and $100 \mathrm{mg})$. In each session food was delivered three to seven times; (3) 30 min recording after the feeding tests, the mouse can drink, explore and sleep in the recording chamber. Each feeding test was separated by a 1-day break to keep the mouse motivated for the feeding tests.

\section{Recording of Regular Chow Induced Activity of FRNs} Chow pellet (weight of each pellet was $25 \pm 5 \mathrm{mg}$ ) was used for the detection of FRNs. The food was delivered at a rate of $3 \mathrm{~min}$ per pellet, and each session contained seven times food delivery. The fasted mouse usually picked up the food within $15 \mathrm{~s}$ after delivery and continuously ate until it finished the whole pellet. Recordings of mice which didn't pick up food within $15 \mathrm{~s}$ or were disrupted during food intake were excluded from the data analyses.

\section{Recording of Activity of FRNs Induced by Intake of Different Amounts of Food}

In the food amount test, each chow pellet was cut and weighed. The food was delivered seven times with 3 min intervals (mean weight of each food pellet was $25 \pm 5 \mathrm{mg}$ in session 1 ), or five times with 5 min intervals (mean weight of each food pellet was $50 \pm 10 \mathrm{mg}$ in session 2), or three times with $9 \mathrm{~min}$ intervals (mean weight of each food pellet was $100 \pm 10 \mathrm{mg}$ in session 3 ). Each animal was sequentially processed through three sessions 
with the interval of $24 \mathrm{~h}$ to keep them motivated for food intake in each session.

\section{Recording of Activity of FRNs Induced by Intake of Distinct Food}

The mice were subjected to two sessions: regular chow and cheese (mean weight of each pellet was $25 \pm 5 \mathrm{mg}$ ), starting with regular chow, and each session was separated by 1 day.

\section{Electrophysiology}

\section{Implantation of Chronic Electrodes}

Thirty-two channel chronic electrodes were hand-made, consisting of eight tetrodes and one specially designed microdrive. The microdrives were manually assembled as described previously (Lin et al., 2006). The tetrodes were made with $\Phi 0.0005$ inch nichrome wires (Stablohm 675, California Fine Wire Company, CA, USA). Eight tetrodes were loaded into the micro-drive via a guiding tube and were arranged in parallel order. Assembled electrodes were gold plated and impedance of each channel was measured between 250 and $350 \mathrm{kOhm}$. During implantation, surgery animals were anesthetized with $1.0 \%$ pentobarbital and then placed into a stereotaxic frame. Bregma position and horizontal level were aligned during implantation. Tetrodes tips were implanted above $0.5 \mathrm{~mm}$ of the hypothalamus and the microdrive was fixed on the skull by six screws and dental cement. Three to five days after the mice recovered from the surgery, tetrodes were propelled $100-200 \mu \mathrm{m}$ per day into the target area (AP: $-2.0 \mathrm{~mm}$; ML: $2.0 \mathrm{~mm}$, DV: $5.0 \mathrm{~mm}$ ) followed by the in vivo recording.

\section{In vivo Recording and Spike Sorting}

Video signal captured by CinePlex Behavioral Research System (Plexon, Inc., TX, USA) and electrophysiological signal acquired by Multichannel Acquisition Processor (MAP) Data Acquisition System (Plexon, Inc., TX, USA) were synchronized. NI USB6501 Digital input/output board (National Instrument) served as feedback control of behavioral tests. The local field potentials were sampled at $1000 \mathrm{~Hz}$ with low pass filter while spike waveforms of AP were sampled at $40 \mathrm{kHz}$. Threshold of spikes was manually set in each channel to get the best noise-signal ratio. One thousand four hundred microseconds of whole spike duration with $200 \mu \mathrm{s}$ pre-spike waveforms were sampled to capture the full AP waveform of hypothalamus unit. Offline Sorter (Plexon, Inc., TX, USA) was used for spike sorting manually after recording. Each waveform was aligned; principal component analyses (PCA) features were used to sort spike waveforms into separated clusters: units with refractory period larger than $1500 \mu$ s $(<0.1 \%$ error) were accepted as one single neuron. Maximum 7 units were well-sorted on single tetrode in hypothalamus (see Supplementary Figure 2).

\section{Data Analysis}

Neuroexplorer 3.2 was used to draw the rate histogram and perievent time histogram (PETH). MATLAB 2014b, Origin 9.0 and Sigmaplot 12.0 were used in statistical analyses. PETH was the main method to detect feeding response and analyze features of all FRNs. The y axis represents the average frequency of FRNs' response during five times of repetitive food intake, while the $\mathrm{x}$ axis represents the time scale ranging from -30 to $90 \mathrm{~s}$ of each feeding trial. The zero point of $\mathrm{x}$ axis was aligned with feeding start time by analysis of video recording. The spike time of AP is plotted in lines above each PETH, five rows indicate five repetitive trials. The feeding duration was defined by "feeding end time minus feeding start time." The feeding start time was verified in videos of mice grasping food and starting to bite; the feeding end time was also verified in videos of mice finishing eating and starting to move (mice usually stand still during feeding). The response duration of FRNs was defined by response offset (sec) minus response onset (sec), where the response onset and offset were the time point when AP frequency was over three times the standard deviation ( $99 \%$ confidence) of baseline firing rate.

\section{Response Separation of Feeding Related Neurons}

We characterized each type of FRNs based on a combination of the three parameters in PETH (peak response, peak latency, and peak decay). The peak response was calculated as the maximum or the minimum frequency after feeding start minus baseline firing rate, this may vary in different types of FRNs, e.g., Type I and II FRNs' maximum frequency was higher than the baseline firing rate, thus the peak response was positive; Type III and IV FRNs' peak response was negative because the baseline firing rate was usually higher than the frequency during food intake, thus the minimum frequency was used in calculation; the latency was defined as the time point of maximum frequency of response plus the response onset, then divided by the firing duration. The latency differentiated the fast response from the slow response in initiation of food intake. The decay was calculated as the half decay response divided by the peak response, and the half decay response was taken the AP frequency at middle of response peak time and offset time, then minus baseline firing rate; the decay separated the sustainable discharge property of FRNs during food intake.

Two parameters were used to distinguish GABAergic neurons from principal cells in FRNs: Trough to peak duration of the extracellular spike waveforms was calculated by the time of peak after trough minus the trough time (Figure 6B). Baseline firing rate was defined by the number of spikes divided by the time (seconds) in pre-feeding control section. Both trough to peak duration and baseline firing rate were widely used in several in vivo recording studies. (Barthó et al., 2004; Vigneswaran et al., 2011; Tsunada et al., 2012) We employed two thresholds in baseline firing rate $(5 \mathrm{~Hz})$ and trough-to-peak duration $(0.42$ $\mathrm{ms}$ ) to divide FRNs into putative glutamatergic neurons, putative GABAergic neurons and undetermined neurons (Barthó et al., 2004; Ison et al., 2011).

\section{Pharmacology}

Mice subjected to regular diet were placed in the empty recording chamber and recorded for $1 \mathrm{~h}$ at basal state. After they were i.p. injected with vehicle $(0.9 \%$ saline; $10 \mathrm{ml} / \mathrm{kg}), 2$-D-Glucose (Sigma; $2 \mathrm{~g} / \mathrm{kg}$ b.w.), and leptin (ProSpec Inc.; $1 \mathrm{mg} / \mathrm{kg}$ b.w.) and recorded for $2 \mathrm{~h}$ without any interruptions. Each animal underwent all sessions with injection of saline, glucose and leptin, separated by 1 day. In the pharmacology test, the response was 
defined as two times standard deviation of baseline response, average AP frequency of $1 \mathrm{~h}$ pre-injection is the baseline response, and the average AP frequency of $1 \mathrm{~h}$ post-injection was used to calculate the response of glutamate or leptin.

\section{RESULTS}

\section{Four Types of Feeding Related Neurons in the Hypothalamus}

In twenty mice implanted with electrodes, the spiking activities of 509 well-sorted hypothalamic units were recorded (Supplementary Figures 1, 2). After detect feeding related neural response in perievent time histogram (PETH, 99\% confidence), the cells with an absolute value of peak response (see Methods) higher than $6 \mathrm{~Hz}$ were characterized as feeding related neurons (FRNs). In total, 50 cells were selected as FRNs from all recorded units recorded (9.8\%, 50/509; Supplementary Table 1). These FRNs were further subdivided into four groups based on their peak response, peak latency and peak decay (Methods and Table 1).

Type I of FRNs showed a sharp increase of firing rate at the beginning of feeding, then a decrease of firing despite continuous food intake (Peak Response $=15.7 \pm 8.9 \mathrm{~Hz}$, Peak Latency $=$ $0.12 \pm 0.08$, Peak Decay $=0.28 \pm 0.11, n=15$ neurons, Figure 1A). Type II of FRNs was characterized by a slow increase of firing during food intake and sustained firing until the end of food intake (Peak Response $=13.6 \pm 6.9 \mathrm{~Hz}$, Peak Latency $=$ $0.54 \pm 0.14$, Peak Decay $=0.62 \pm 0.12, n=14$ neurons, Figure 1B). Type III of FRNs demonstrated sudden inhibition at the beginning of feeding, then recovered quickly during feeding (Peak Response $=-11.9 \pm 4.2 \mathrm{~Hz}$, Peak Latency $=0.11 \pm 0.07$, Peak Decay $=0.56 \pm 0.08, n=9$ neurons, Figure 1C). Type IV of FRNs had gradual decrease of firing and remained silent during feeding (Peak Response $=-14.3 \pm 4.1 \mathrm{~Hz}$, Peak Latency $=0.43 \pm 0.15$, Peak Decay $=0.85 \pm 0.11, n=12$ neurons, Figure 1D). Based on the direction of responses, types I and II can be seen as "ON" response group, while types III and IV as "OFF" response group. The Figure 1E show the average values of the parameters described above for each population of FRNs, and there were significant differences among each group (see $P$-value of $t$-test in Table 2). After feature projection of those characters of all recorded FRNs into the $3 \mathrm{D}$ coordinate system, four unique clusters clearly emerged (Figure 1F).

TABLE 1 | Statistical features of all types of FRNs.

\begin{tabular}{lccccc}
\hline & Type I & Type II & Type III & Type IV & Other cells \\
\hline Cell number & 15 & 14 & 9 & 12 & 459 \\
DG+ & 1 & 4 & 4 & 2 & 28 \\
DG- & 4 & 2 & 2 & 4 & 24 \\
DG N/A & 1 & 1 & 2 & 2 & 88 \\
Leptin+ & 0 & 1 & 1 & 0 & 20 \\
Leptin- & 3 & 4 & 3 & 4 & 13 \\
Leptin N/A & 1 & 1 & 1 & 2 & 149
\end{tabular}

The FRNs of different types (I, II, III, and IV) simultaneously responded to the beginning of food intake, although the latency of response onset may vary between different types (Figure 2). Here, we listed three different types of FRNs simultaneously recorded in two animals: type I, II, and III in mouse 16 (Figure 2A), type I, IV, and IV in mouse 17 (Figure 2B). Both PETHs (Figures 2A,B; left panel) and rate histograms (Figures 2A,B; right panel) exhibit synchronized firing patterns among different types. When we aligned the timing of food intake in PETHs, we found that type IV FRNs often respond when the animal aware the food was delivered (before the animal starts to eat), type I and III FRNs respond exactly at the time the animal takes the first bite, and finally a late response can be found in type II FRNs within few seconds after feeding started. Importantly, all these type of FRNs were firing robustly during feeding, and their basal firing rate remained relatively stable in non-feeding periods, including exploratory behavior and rest.

\section{Response of Feeding Related Neurons Correlates with Food Amount}

Next, we tested whether different amounts of food $(25,50$, and $100 \mathrm{mg}$ ) affect the firing properties of FRNs. We recorded the typical response of "ON" (types I and II) and "OFF" group of FRNs among the three food amount trials (Figure 3). On average, the feeding duration increased with food amount: $31 \pm 6 \mathrm{~s}$ after intake of $25 \mathrm{mg}, 52 \pm 4 \mathrm{~s}$ after intake of $50 \mathrm{mg}$ and $84 \pm 15 \mathrm{~s}$ after intake of $100 \mathrm{mg}$ ( $N=8$ mice). In parallel, the firing duration of FRNs also increased with food amount: $24 \pm 7 \mathrm{~s}$ (25 mg), $38 \pm 6 \mathrm{~s}$ (50 mg), $70 \pm 17 \mathrm{~s}(100 \mathrm{mg})$ in the "ON" group of FRNs (Figure 3B, $n=21$ neurons), and $31 \pm 4 \mathrm{~s}$ (25 mg), $39 \pm$ $10 \mathrm{~s}$ (50 mg), $67 \pm 10 \mathrm{~s}$ (100 mg) in the “OFF" group of FRNs (Figure 3D, $n=17$ neurons). Linear regression showed that excitation or inhibition response of FRNs were closely related to food amount as well as feeding duration, both in the "ON" $\left(r^{2}=\right.$ $0.77)$ and "OFF" group $\left(r^{2}=0.74\right)$. In contrast, peak response, peak latency and peak decay of both "ON" and "OFF" groups remain unchanged in the three food amount tests. (see $p$-value of $t$-test in Table 2).

\section{Response of Feeding Related Neurons Is Not Affected by Food Types}

We then asked whether activity of FRNs depends on specific food types. We recorded FRNs neurons exposed sequentially to regular chow and cheese. As can be seen in the comparison of either three "ON" group FRNs (Figure 4A) and three "OFF" group FRNs (Figure 4B), firing patterns between regular chow and cheese revealed that neither peak response, peak latency, peak decay nor response duration had any difference either in the "ON" (Figure 4C, $n=9$ neurons, $N=6$ mice) or "OFF" (Figure 4C, $n=7$ neurons, $N=6$ mice) group of FRNs (see $p$-value of $t$-test in Table 2).

\section{Effects of Glucose and Leptin on Feeding Related Neurons}

Next, we asked whether recorded hypothalamic cells are sensitive to nutritional and hormonal signals-glucose and leptin. In 8 

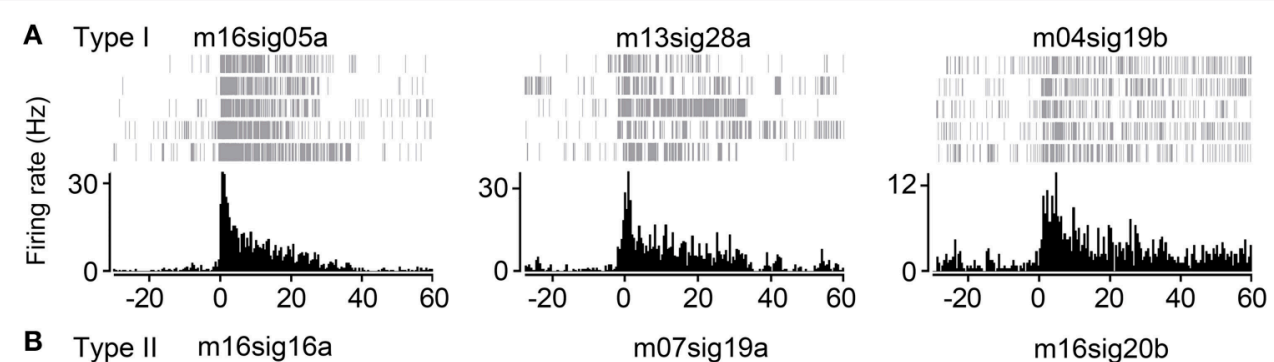

B Type II m16sig16a
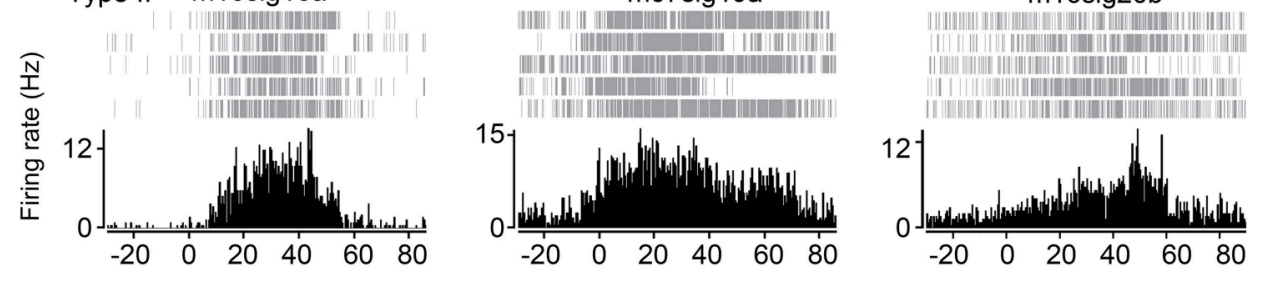

C Type III m20sig26a
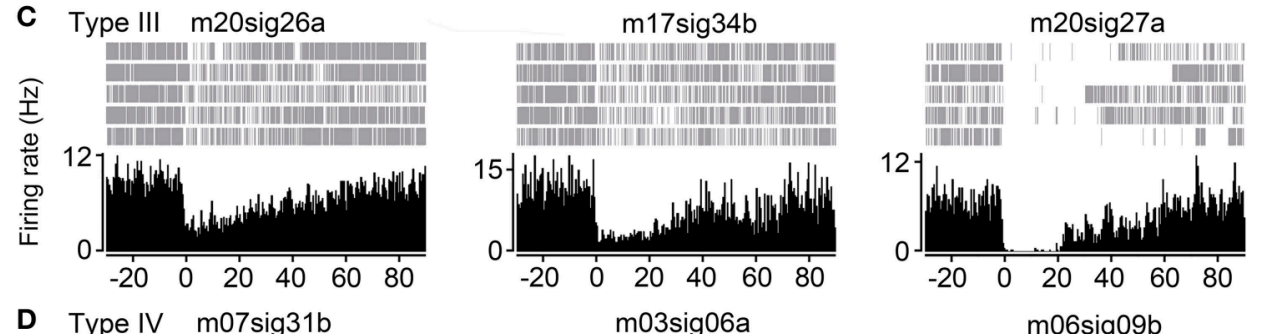

D Type IV m07sig31b

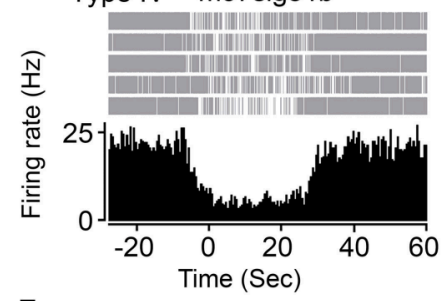

E
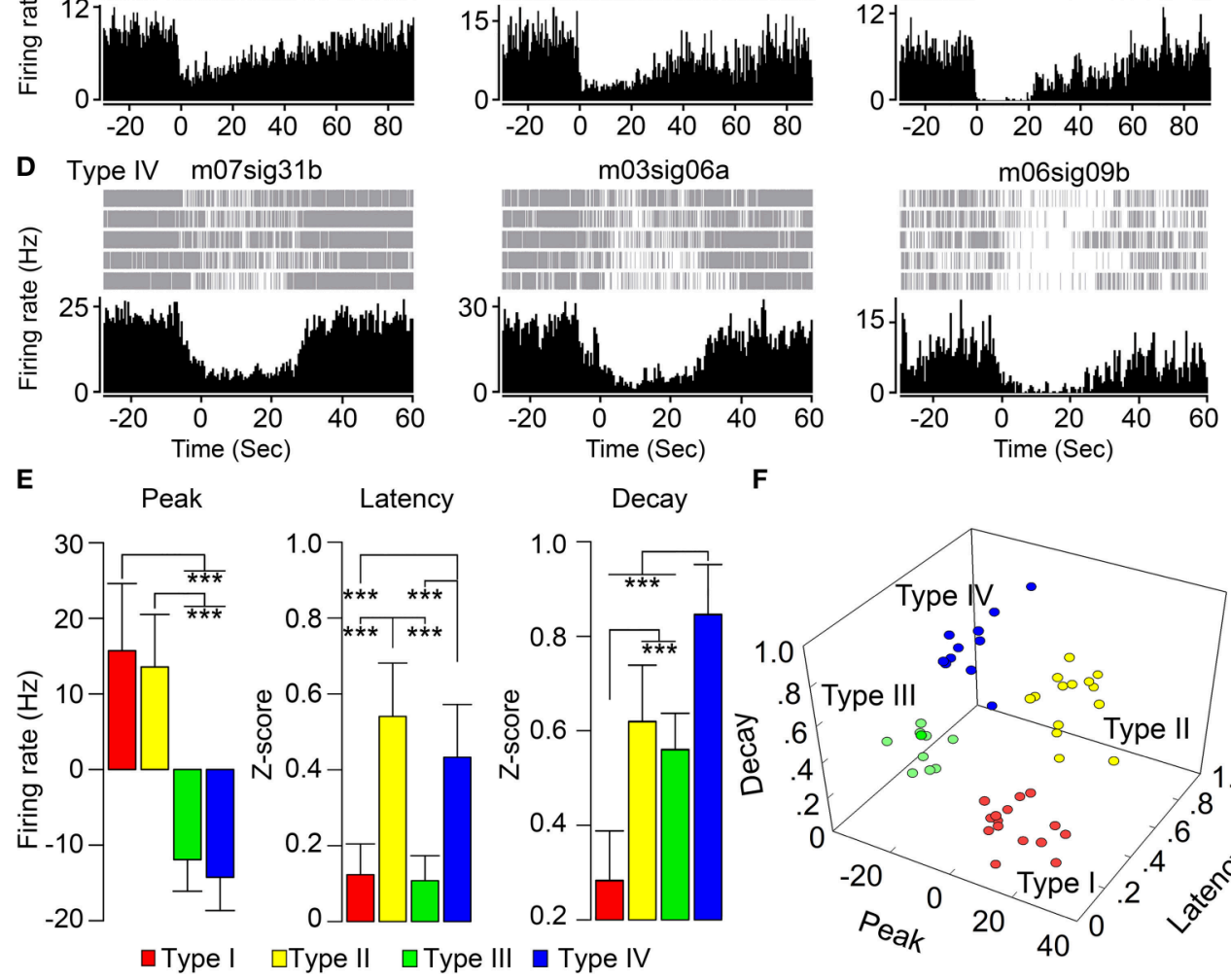

$F$

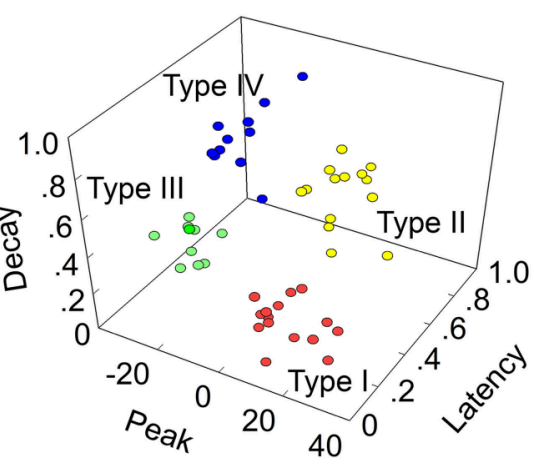

FIGURE 1 | Distinct feeding related firing patterns of hypothalamic neurons. (A) Type I of FRNs with the sharp increase of firing rate at beginning of food intake. (B) Type II of FRNs with an increase of firing rate. (C) Type III of FRNs with the sharp decrease of firing rate. (D) Type IV of FRNs with sustain decrease of firing rate during feeding. (E) Feeding related firing patterns of FRNs were compared by three parameters of their perievent time histogram: peak response, peak latency and peak decay ${ }^{* * *} p<0.001$, multiple $t$-test with Bonferroni correction). (F) Four types of FRNs were separated in 3D scatters graph.

mice, 140 units were tested for glucose and 182 units were tested for leptin. Among them 37\% (52/140) units responded to glucose: $20 \%(28 / 140)$ were activated and $17 \%$ (24/140) were inhibited, while only $18 \%$ (33/182) units responded to leptin: $7 \%(20 / 182)$ were activated and 11\% (13/182) were inhibited (Table 1$)$.
Further, we asked whether the recorded FRNs are sensitive to glucose and leptin. Due to the instability of extracellular signals and cell death in chronic recording condition, only parts of the FRNs were tested: 29 FRNs were tested for glucose and 21 FRNs were tested for leptin ( $N=8$ mice). We found that $79 \%(23 / 29)$ 
of FRNs responded to glucose, either by an increase (11/29) or decrease $(12 / 29)$ of firing rates (Figure 5A middle panel), while $21 \%(6 / 29)$ of FRNs did not respond to injection of glucose. Similar results were obtained after the injection of leptin: $76 \%$ $(16 / 21)$ of FRNs responded to leptin, among which $67 \%(14 / 21)$ of FRNs decreased firing rate, $24 \%(5 / 21)$ of FRNs did not change their firing rate and only $10 \%(2 / 21)$ of FRNs increased firing rate (Figure 5A; right panel).

Ruled out the none response cells, majority Type I were inhibited by both glucose (4/5) and leptin (3/3); and Type II were

TABLE 2 | The $p$-values of multiple $t$-tests with Bonferroni correction for all possible combinations between FRNs types, food amount, and food type $\left({ }^{\star * *} p<0.001\right)$.

\begin{tabular}{|c|c|c|c|c|}
\hline Groups combination & Refer to & Peak & Latency & Decay \\
\hline Type I-II & Figure 1E & 0.85 & $1.6 \mathrm{e}-9\left(^{(* \star}\right)$ & $7.8 \mathrm{e}-8\left(^{\star \star \star}\right)$ \\
\hline Type I-III & Figure 1E & $2.0 e-9\left({ }^{\star \star *}\right)$ & 0.93 & $6.2 \mathrm{e}-7\left(^{* * \star}\right)$ \\
\hline Type I-IV & Figure 1E & 1.9 e- $8\left(^{(* *}\right)$ & $\left.2.2 \mathrm{e}-6^{* \star \star}\right)$ & $2.2 \mathrm{e}-12\left(^{\star \star \star}\right)$ \\
\hline Type II-III & Figure 1E & 9.0 e- $9\left(^{(\star \star}\right)$ & 6.3 e- $9\left(^{* \star \star}\right)$ & 0.39 \\
\hline Type II-IV & Figure 1E & $\left.2.1 \mathrm{e}-9^{(\star *}\right)$ & 0.17 & $1.9 e-4\left(^{\star \star \star}\right)$ \\
\hline Type III-IV & Figure 1E & 0.79 & $3.5 \mathrm{e}-6\left(^{(\star \star}\right)$ & $2.8 e-6\left(^{* \star \star}\right)$ \\
\hline ON: 25-50 mg & Figure 3A & 0.14 & 0.60 & 0.99 \\
\hline ON: 50-100 mg & Figure 3A & 0.50 & 0.62 & 0.94 \\
\hline ON: 25-100mg & Figure $3 \mathbf{A}$ & 0.72 & 0.99 & 0.96 \\
\hline OFF: 25-50 mg & Figure $3 C$ & 0.21 & 0.45 & 0.42 \\
\hline OFF: 50-100 mg & Figure $3 C$ & 0.02 & 0.99 & 0.10 \\
\hline OFF: 25-100mg & Figure 3C & 0.03 & 0.88 & 0.58 \\
\hline ON: cheese-control & Figure 4C & 0.31 & 0.94 & 0.14 \\
\hline OFF: cheese-control & Figure 4C & 0.41 & 0.83 & 0.22 \\
\hline
\end{tabular}

activated by glucose (4/6) but inhibited by leptin (4/5); most of Type III were also activated by glucose $(4 / 6)$ and inhibited by leptin (3/4); majority Type IV were inhibited by both glucose $(4 / 6)$ and leptin (4/4) (Figures 5B,C). We did not find any difference in FRNs' firing rate after giving saline.

\section{Electrophysiology Character Shows FRNs Are Mostly Putative GABAergic Neurons}

The baseline firing frequency and the spike duration were two well-established criteria to separate GABAergic neurons from glutamatergic neurons (Buzsáki and Vanderwolf, 1983; Singer and Gray, 1995; Skaggs and McNaughton, 1996). We used trough to peak duration (TPD, criteria 1, Figure 6B) and baseline firing rate (BFR, criteria 2) to sort all recorded FRNs plotted in $2 \mathrm{D}$ scatters. Then we set the trough to peak threshold to $0.42 \mathrm{~ms}$ and baseline firing rate threshold to $5 \mathrm{~Hz}$ (Barthó et al., 2004; Ison et al., 2011; Peyrache et al., 2015), and separate scatters into four quadrants. The classifications based on both criteria were shown in Figure 6A. 2D plot of trough to peak duration and baseline firing rate exhibit at least two groups of FRNs: (1) putative GABAergic neurons with TPD $<0.42 \mathrm{~ms}$ and BFR $>5 \mathrm{~Hz}$ (Figure 6A, quadrant IV); (2) putative principal cells which were commonly considered as glutamatergic neuron with TPD $>0.42 \mathrm{~ms}$ and $\mathrm{BFR}<5 \mathrm{~Hz}$ (Figure 6A, quadrant II). Comparing characteristics of four types of FRNs with their firing pattern, we found that 28 out of 50 FRNs have characteristics of putative GABAergic neurons and 8 of them have characteristics of putative principal cells, other 14 remain vague between GABAergic neurons and principal cells. As a conclusion of separation: In 15 type I FRNs (2 GABA, 3 PC, 10 undetermined); in 14 type II FRNs (4 GABA, 5 PC, 5 undetermined); in 9 type III
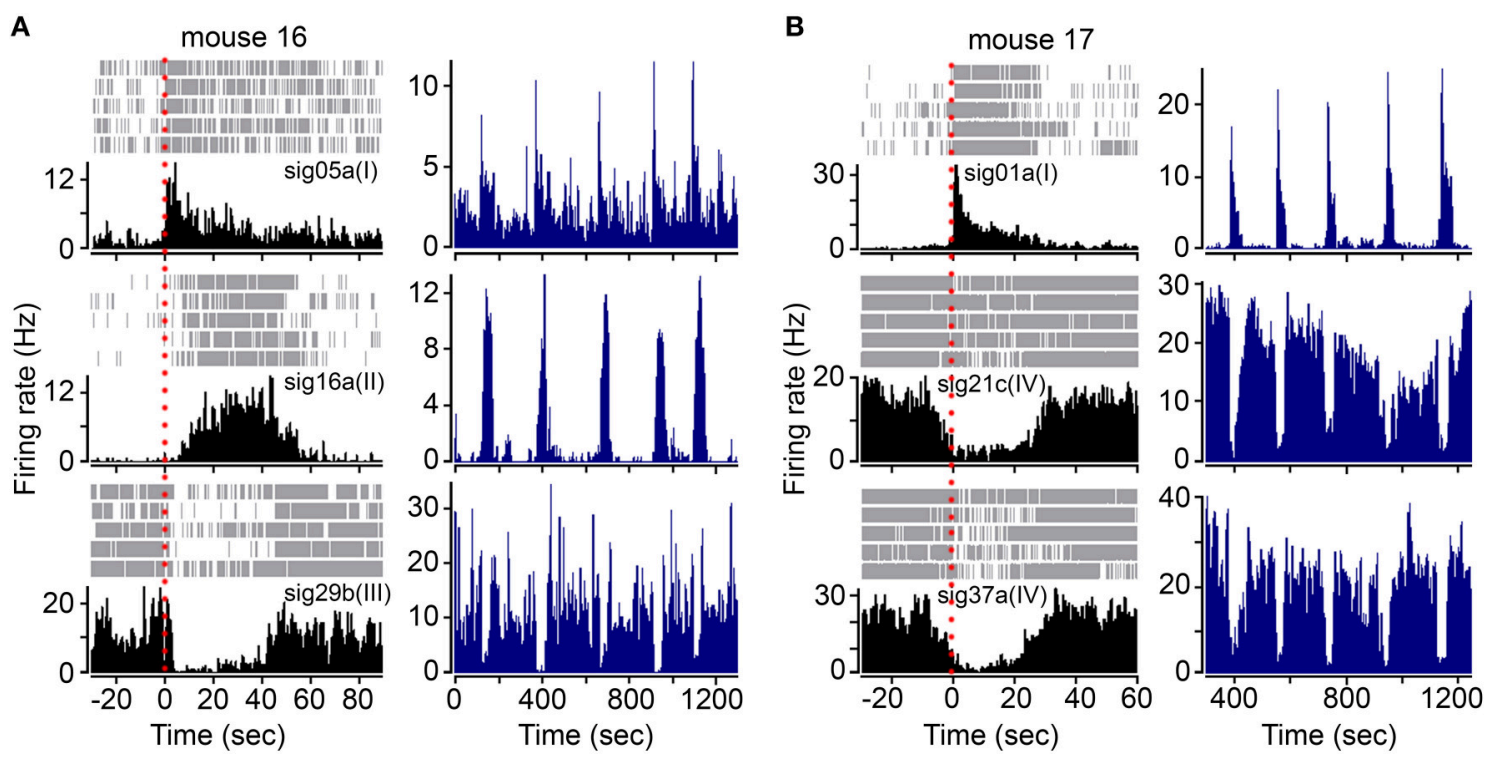

FIGURE 2 | FRNs orchestrate during food intake in type specific pattern. (A) Three simultaneously recorded different types of FRNs (type I, II, and III) during feeding behavior in one mouse. (B) Three simultaneously recorded different types of FRNs (type I, IV, and IV) during feeding behavior in another mouse. Onset of feeding was aligned by red dashes in PETH (left panel). Type I and III FRNs peaked exactly at the beginning of food intake, while type II and IV respond slowly and peaked in the middle of food intake. 


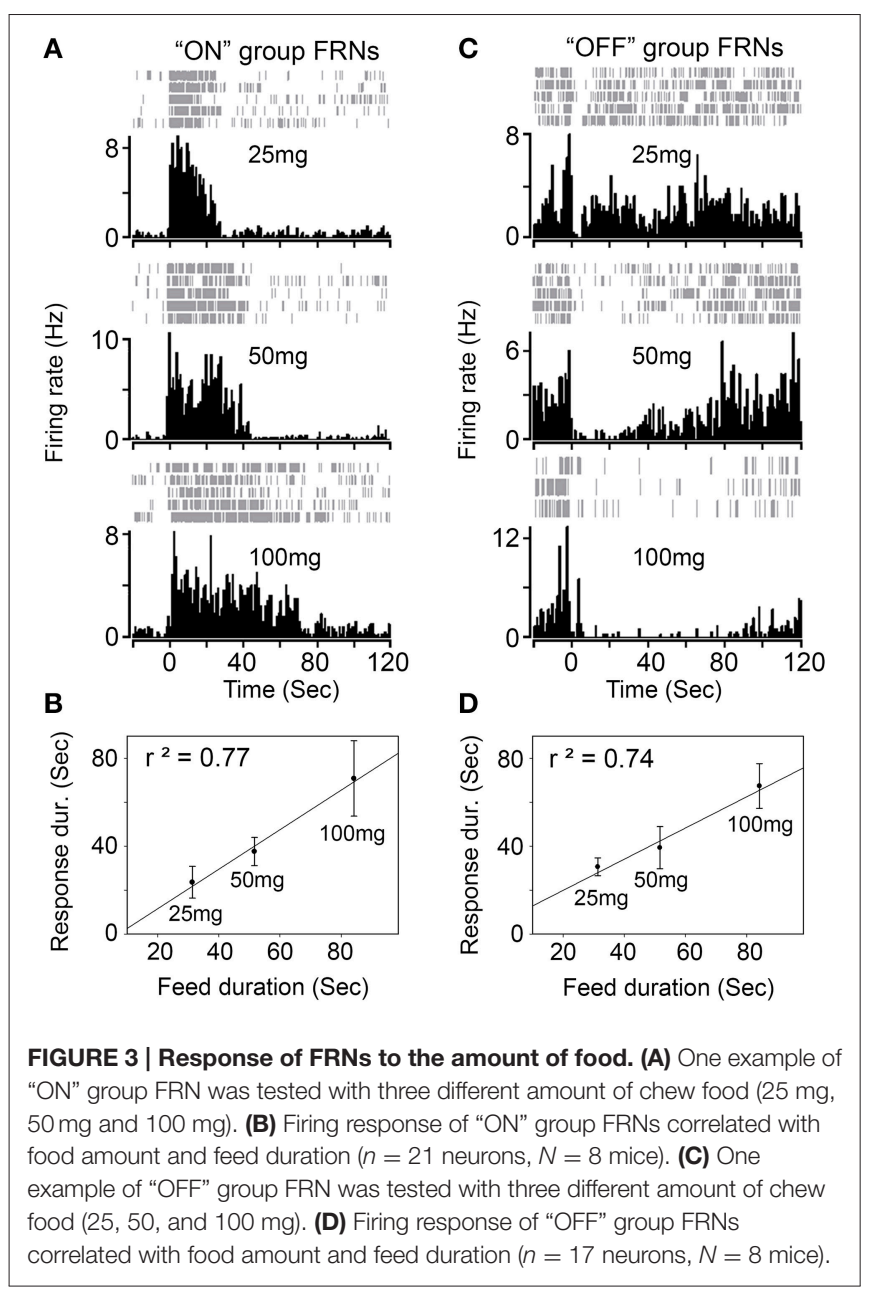

FRNs (8 GABA, 1 undetermined); in 12 type IV FRNs (12 GABA) (Figure 6B).

\section{DISCUSSION}

\section{Four Types of FRNs}

The LH is composed of heterogeneous groups of cells, often expressing various neuropeptides concomitantly with GABA or glutamate. In our study, we identified hypothalamus FRNs, which were classified into four functional types based on peak direction, latency and duration of responses. Types I and II FRNs were activated during food intake (increased firing rate with fast or slow latency respectively), representing the "ON" group of FRNs. On the contrary, types III and IV were inhibited during feeding (decreased firing rate or total cessation of firing), therefore representing the "OFF" group of FRNs. Further, subtypes in the "ON" group were separated by onset of peak response, type I with immediate onset of discharge to the maximum frequency, while type II with delayed discharge and gradually reaching of maximum frequency. The "OFF" group of FRNs can be separated by decay value of response, type III with fast decay of discharge inhibition and type IV with long decay of discharge inhibition.
These four types of FRNs seem to encode all of the basic properties of feeding behavior in the LH.

It is interesting that some types of FRNs respond "prior" to feeding behavior compared to other types: e.g., type IV FRNs decrease firing rate and some type II FRNs has an instant burst firing at the moment when the animal saw the food. We suspect that this pre-feeding neural activity may correlate with alert or arousal response. From the shape of the neural response, we hypothesize that type I and type III were paired in encoding the initiation of food intake (e.g., bite and taste), while type II and type IV may serve to sustain the feeding process (e.g., swallow and digest).

\section{FRNs Activity Depends on Duration of Food Intake}

We found that increasing the amount of the meal gradually increases the response duration of FRNs, but not the peak frequencies or the other features of responses. These results suggest that FRNs' response basically follows the duration of mice eating. The "ON" group of FRNs increases firing after feeding start and ceases firing before feeding ends. The "OFF" group of FRNs decreases firing during the feeding process and slowly recovers after feeding ends. The characters of response (onset, peak) remain unchanged as the meal increased, which indicates the specificity of response was robust in each type of FRNs.

We tested the FRNs' response to different food types, and found no significant difference between cheese and chow food groups in either the same neuron or in cell populations (Figure 4). In some trials, we used chocolate, but we still found no obvious difference compared with cheese or chow pellet. To our observation, few FRNs respond to the sound of food delivery, more like an alert or arousal response, which was similar to response of orexin neurons (Mileykovskiy et al., 2005). Indeed, there are other stimuli which may activate LH neurons, like the taste of food (Burton et al., 1976; Schwartzbaum, 1988). In our study, we excluded neurons that responded to sound or smell, but did not respond to food intake. We also tested false food as a control object to real food, but the mice refused to approach fake food after being cheated two or three times, thus no robust response of the cell is recorded, although in the first or second trial, the initial response of fake food is similar to real food. Until animals recognize the object as food, they will not start to bite, thus it is hard to detect FRNs respond to non-food object. The FRN response during sleep remains constant; the "ON" group of FRNs' baseline firing rate was very low across all situations, besides food intake, and the "OFF" group of FRNs' baseline firing rate was high when awake, but decreased firing rate or changed into phasic firing during sleep. Our results are in accordance with the studies done by other researchers (Hassani et al., 2009, 2010).

Regarding the circadian rhythm of FRN's activity, we continuously recorded FRNs for $72 \mathrm{~h}$ to demonstrate if there is a circadian clock in the firing rhythm. Indeed, we found that there is higher discharge in the evening when the animal usually gets up to eat; the discharge lasts for about $2 \mathrm{~h}$ and then goes back to baseline and stays constant during rest hours. Another important issue is that social isolation can alter the HPA axis 

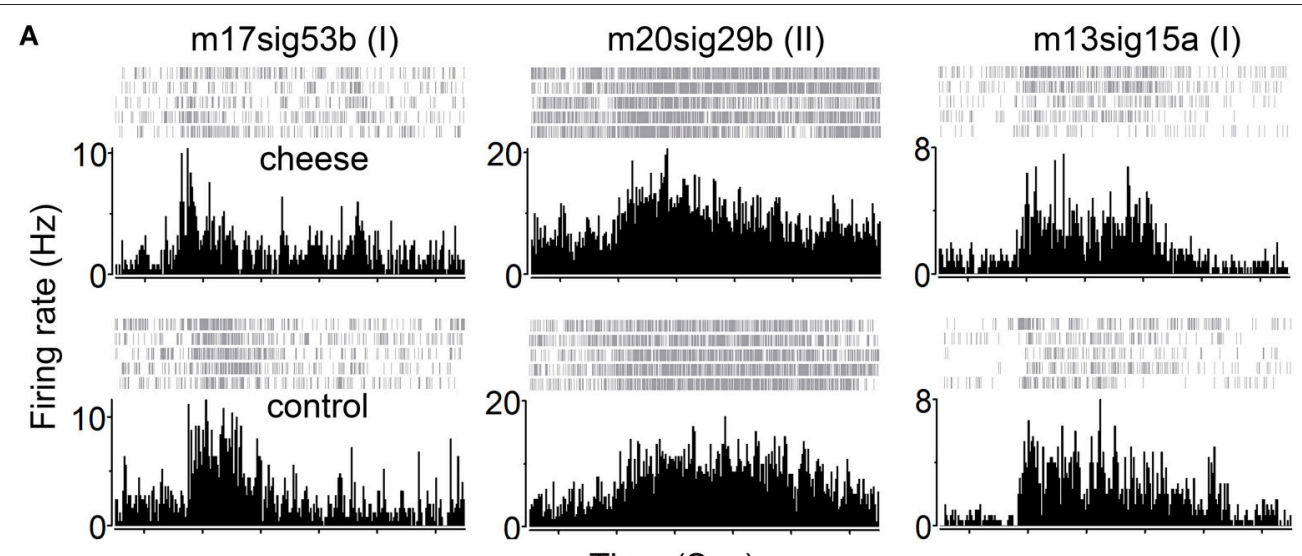

Time $(\mathrm{Sec})$
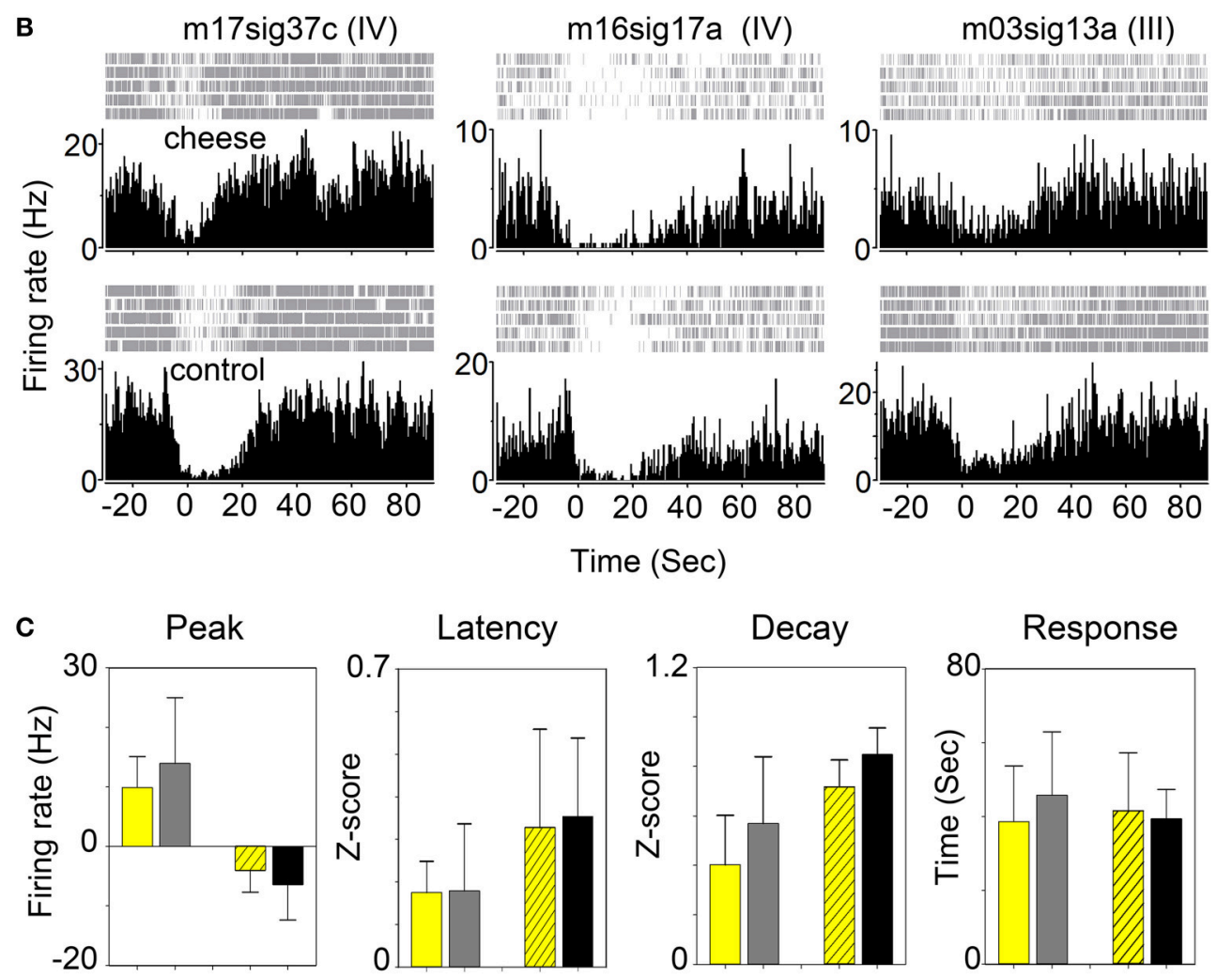

ON group with cheese

OFF group with cheese

ON group with control food OFF group with control food

FIGURE 4 | Response of FRNs to distinct food type. (A) Three "ON" group FRNs in cheese test (top panels) and control chow food test (bottom panels). (B) Three "OFF" group FRNs in cheese test (top panels) and control chow food test (bottom panels). (C) Statistical data showed the variations of peak response, peak latency, peak decay and firing duration between cheese and chow food in both ON group ( $n=9$ neurons, $N=6$ mice) and OFF group ( $n=7$ neurons, $N=6$ mice). No significant difference among any parameter in each group was found.

as well as affect the neural activity (Serra et al., 2005; AgísBalboa et al., 2007). Therefore, we cannot exclude the effects of stress on both food intake and excitability of recorded neurons. However, individual housing of mice was only possible in our experimental setup because microdrives with electrodes on the head of each mouse are extremely fragile and co-housed mice can easily damage them.

From observations described above, we concluded that the firing of FRNs is more dependent on food intake duration rather than on types of food. Although, the baseline firing of FRNs may 
A

FRN types Glucose response Leptin response

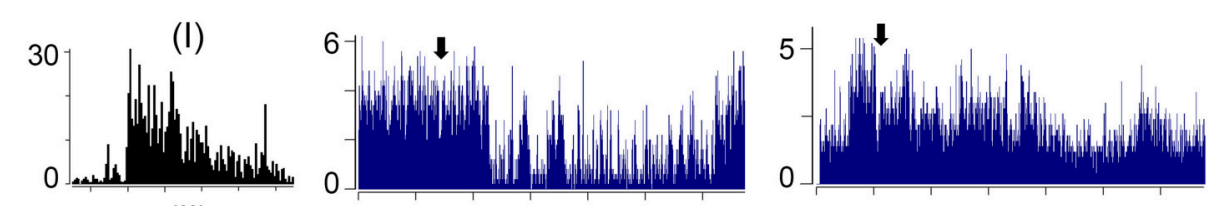

(II)
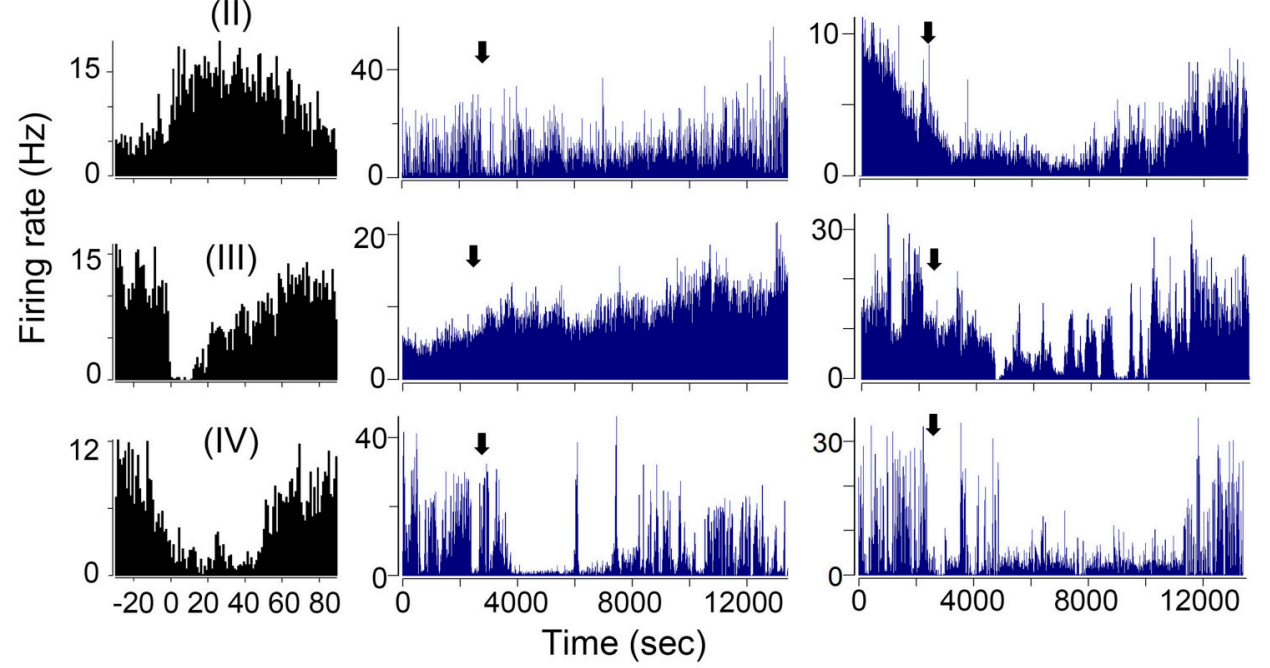

B

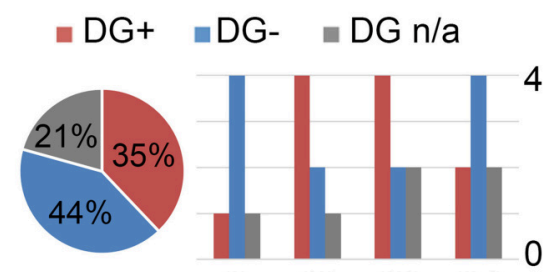

(I)

(II)

(III) (IV)

C $\quad$ - Lep+ $=$ Lep- $\because$ Lep n/a

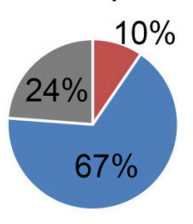

$67 \%$

FIGURE 5 | Effects of glucose and leptin on FRNs. (A) Four examples of each type FRNs respond to glucose and leptin. In first line type I FRN's spike rate decreased after glucose and leptin i.p. delivery. In second line type II FRN's spike rate increased after glucose delivery but decreased after leptin i.p. delivery. In third line type III FRN's firing rate decreased after glucose i.p. delivery but increased after leptin i.p. delivery. In fourth line type IV FRN's firing rate decreased both after glucose and leptin i.p. delivery. (B) Left panel was the ratio of all FRNs' response to glucose ( $n=29$ neurons, $N=8$ mice), right panel is statistical results of each type FRNs' response to glucose. Similarly, the statistics of FRNs' response to leptin were showed in left panel (C) was the ratio of all FRNs' response to leptin ( $n=21$ neurons, $N=8$ mice) while the right panel was statistical results of each type FRNs respond to leptin.

change with circadian rhythm, the response of FRNs in food intake is much stronger.

\section{Majority Recorded FRNs Are Glucose and Leptin Sensing Neurons}

Nutritional and hormonal signals, such as glucose or leptin, led to opposite responses of FRNs to food intake (Figure 5). More than half of the FRNs were activated by glucose, and over one-third of the FRNs were inhibited, while most FRNs were inhibited and only few were activated by leptin. However, if we ruled out the FRNs and see all the other recorded cells in the hypothalamus, this ratio dropped much lower. Only 20\% were activated and $17 \%$ were inhibited by glucose. Comparing the ratio of glucose response recorded in all cells in the hypothalamus, we can infer that the majority of FRNs are glucose-sensing neurons (Oomura et al., 1974). The four types of FRNs' pharmacology response were not equally distributed (Figures 5B,C) which suggests that each type may have their unique chemical features and receptors. Interestingly, the "ON" group contains more FRNs activated by glucose, while the "OFF" group is composed of cells that were preferentially inhibited by glucose. This finding may indicate bidirectional regulation of energy balance by the "ON" and “OFF” groups of FRNs.

The high number of FRNs responding to leptin suggests that the majority of FRNs expresses the leptin receptor (Figure 5C). The different distribution among types also implies a bidirectional network of body weight regulation (e.g., more FRNs were inhibited rather than activated by leptin). The majority of FRNs responded to nutritional and hormonal signals, 


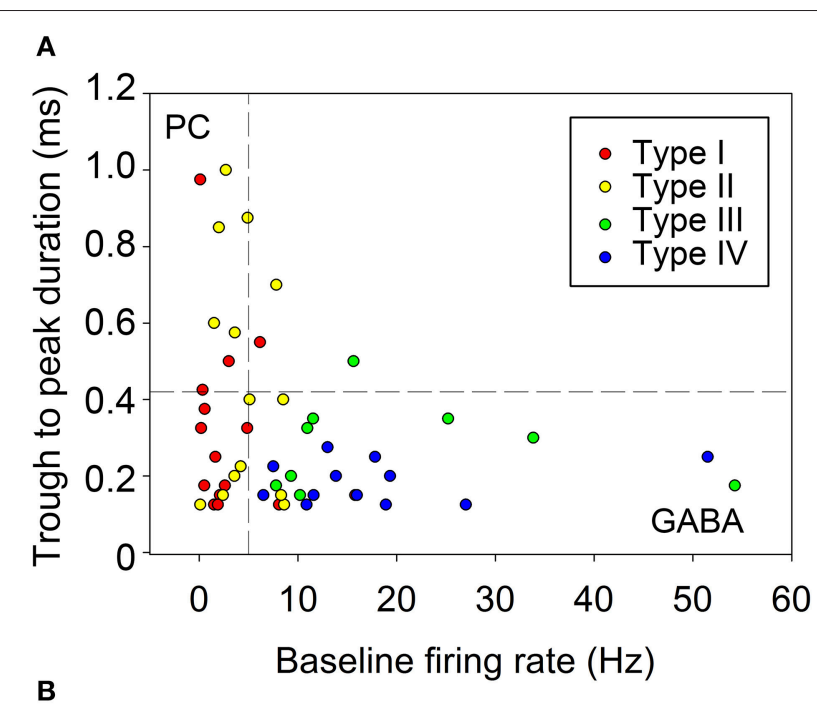

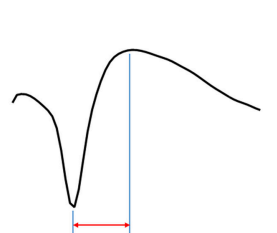

Trough to peak duration

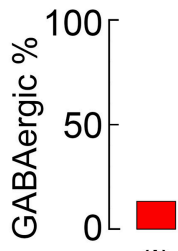

(I)

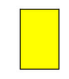

(II)

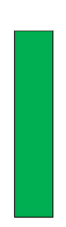

(III) (IV)
FIGURE 6 | Discrimination of putative GABAergic and glutamatergic FRNs. (A) We set the trough to peak threshold of $0.42 \mathrm{~ms}$ and baseline firing rate threshold $5 \mathrm{~Hz}$ to separate scatters into four quadrants. Putative glutamatergic neurons were in quadrant II (TPD $>0.42 \mathrm{~ms}, \mathrm{BFR}<5 \mathrm{~Hz}$ ), putative GABAergic neurons were in quadrant IV (TPD $<0.42 \mathrm{~ms}, \mathrm{BF} R>5$ $\mathrm{Hz}$ ) and undetermined cells are in quadrant I and III. $26 \mathrm{FRN}$ were set as putative GABAergic neurons and 8 FRNs were set as putative glutamatergic neurons, remaining 16 FRNs were set as undetermined cells. (B) Trough to peak duration of FRNs' extracellular spike waveform was showed as example in the left. Composite of each type of FRNs were showed in the right, each color represented GABAnergic neuron in each type FRNs. Type I \& II FRNs had a mixed composition of putative glutamatergic and GABAergic neurons, although $66 \%$ type I and $36 \%$ type II remain undetermined. $89 \%$ type III and 100\% type IV FRNs belonged to putative GABAergic neuron.

indicating that they play an important role in energy balance and food intake regulation; however, the "biased" distribution of inhibition and activation response among four types of FRNs suggests that there may be a dominant type of cells in each type of FRN. The "ON" group possibly consists of peptidergic cells, which are inhibited by glucose, and the "OFF" group of FRNs can be inhibitory neurons, expressing leptin receptors. The results fit our finding that $40 \%$ of the GABAergic neurons in the $\mathrm{LH}$ are inhibited by glucose (Marsh et al., 2002; Karnani et al., 2013).

\section{Are FRNs GABAergic or Glutamatergic Neurons?}

According to the high mean firing rates and narrow duration of action potentials (APs), the majority of FRNs appear to be putative GABAergic neurons, which is supported by recent findings (Karnani et al., 2013; Jennings et al., 2015).
Another small part of FRNs is putative glutamatergic neurons representing the main type of neuropeptidergic neurons, and their firing pattern resembles random firing of neurons in the ventromedial nucleus (Sabatier and Leng, 2008).

Baseline firing rate is a key parameter to define GABAergic neurons. Although, peak response can be the same during feeding, GABAergic neurons have a much higher basal firing rate than pyramidal cells (Ison et al., 2011). Since types III and IV of FRNs have a relatively high baseline firing rate and narrow spike durations, the most of these two types FRNs are likely to be GABAergic neurons. (Figure 6).

Type I of FRNs has an acute response on feeding, and most of them were inhibited by both glucose and leptin. Furthermore, at least half of FRNs exhibited the same AP waveform and baseline firing similar to glutamate neurons. Based on these two features, we speculate that Type I FRNs are orexinergic neurons (Mileykovskiy et al., 2005) activated during feeding behavior (Akiyama et al., 2004; Mieda et al., 2004).

Type II of FRNs were activated by glucose and inhibited by leptin, and their electrophysiology parameters represented both GABA and glutamatergic neurons. This mixed composition is likely reflects the nature of neuropeptide neurons as they can simultaneously express GABA (van den Pol et al., 2004) and glutamate (Chee et al., 2015).

The "OFF" group of FRNs is characterized by narrow waveform, high basal firing rate, and inhibition by glucose and activation by leptin. Based on inhibitory responses during feeding, we assume that at least a part of the "OFF" FRNs were LepR expressing GABAergic neurons, as was reported previously (Karnani et al., 2013).

\section{Incorporation of FRNs in LH Network Controlling Food Intake}

Our study revealed the presence in the $\mathrm{LH}$ of "ON" and "OFF" FRNs, which can be bidirectional modulated during food intake. As a possibility, the initiation of feeding behavior can be induced by "ON" cells, which can be reciprocally inhibited by "OFF" cells, receiving extra LH inputs (Elias et al., 1999; Goforth et al., 2014). However, precise interactions of FRNs within the local LH network to control feeding behavior, metabolism, and energy consumption remains further research.

\section{CONCLUSION}

This study found "ON" and "OFF" feeding related neurons in mouse hypothalamus, further divided into four types, which fired synchronously to presumably orchestrate feeding behavior. The activity of FRNs was correlated with food amount, but not food type, and most of them were putative GABAergic neurons. Based on electrophysiological characteristics, electrodes location and sensitivity to glucose and leptin, we propose that FRNs are glucose sensitive neurons, expressing LepR. Incorporation of these groups in the network and their contribution to distinct forms of feeding behavior remains a subject of further research. 


\section{AUTHOR CONTRIBUTIONS}

YT, LL designed the experiments. YT performed surgery and experiments. YT, DB, and LL performed analysis. YT, VG, and LL wrote the manuscript. All of the authors discussed the results at all stages of the project.

\section{ACKNOWLEDGMENTS}

This work was supported by Chinese Scholarship Council (to YT), the Chica and Heinz Schaller Research Foundation and

\section{REFERENCES}

Agís-Balboa, R. C., Pinna, G., Pibiri, F., Kadriu, B., Costa, E., and Guidotti, A. (2007). Down-regulation of neurosteroid biosynthesis in corticolimbic circuits mediates social isolation-induced behavior in mice. Proc. Natl. Acad. Sci. U.S.A. 104, 18736-18741. doi: 10.1073/pnas.0709419104

Akiyama, M., Yuasa, T., Hayasaka, N., Horikawa, K., Sakurai, T., and Shibata, S. (2004). Reduced food anticipatory activity in genetically orexin (hypocretin) neuron-ablated mice. Eur. J. Neurosci. 20, 3054-3062. doi: 10.1111/j.14609568.2004.03749.x

Anand, B. K., and Brobeck, J. R. (1951). Hypothalamic control of food intake in rats and cats. Yale J. Biol. Med. 24, 123.

Baird, J.-P., Rios, C., Gray, N. E., Walsh, C. E., Fischer, S. G., and Pecora, A. L. (2006). Effects of melanin-concentrating hormone on licking microstructure and brief-access taste responses. Am. J. Physiol. Regul. Integr. Comp. Physiol 291, R1265-R1274. doi: 10.1152/ajpregu.00143.2006

Baird, J.-P., Rios, C., Loveland, J. L., Beck, J., Tran, A., and Mahoney, C. E. (2008). Effects of hindbrain melanin-concentrating hormone and neuropeptide $\mathrm{Y}$ administration on licking for water, saccharin, and sucrose solutions. Am. J. Physiol. Regul. Integr. Comp. Physiol. 294, R329-R343. doi: 10.1152/ajpregu.00611.2006

Barthó, P., Hirase, H., Monconduit, L., Zugaro, M., Harris, K. D., and Buzsáki, G. (2004). Characterization of neocortical principal cells and interneurons by network interactions and extracellular features. J. Neurophysiol. 92, 600-608. doi: 10.1152/jn.01170.2003

Boules, M., Cusack, B., Zhao, L., Fauq, A., McCormick, D. J., and Richelson, E. (2000). A novel neurotensin peptide analog given extracranially decreases food intake and weight in rodents. Brain Res. 865, 35-44. doi: 10.1016/S00068993(00)02187-9

Burdakov, D., Luckman, S. M., and Verkhratsky, A. (2005). Glucose-sensing neurons of the hypothalamus. Philos. Trans. R. Soc. B Biol. Sci. 360, 2227-2235. doi: $10.1098 /$ rstb.2005.1763

Burton, M., Rolls, E., and Mora, F. (1976). Effects of hunger on the responses of neurons in the lateral hypothalamus to the sight and taste of food. Exp. Neurol. 51, 668-677. doi: 10.1016/0014-4886(76)90189-8

Buzsáki, G., and Vanderwolf, C. H. (1983). Cellular bases of hippocampal EEG in the behaving rat. Brain Res. Rev. 6, 139-171. doi: 10.1016/0165-0173(83)90 037-1

Chee, M. J., Arrigoni, E., and Maratos-Flier, E. (2015). Melanin-concentrating hormone neurons release glutamate for feedforward inhibition of the lateral septum. J. Neurosci. 35, 3644-3651. doi: 10.1523/JNEUROSCI.4187-14.2015

Clegg, D. J., Air, E. L., Woods, S. C., and Seeley, R. J. (2002). Eating elicited by orexin-a, but not melanin-concentrating hormone, is opioid mediated. Endocrinology 143, 2995-3000. doi: 10.1210/endo.143. 8.8977

de Araujo, I. E., Gutierrez, R., Oliveira-Maia, A. J., Pereira, A. Jr., Nicolelis, M. A., and Simon, S. A. (2006). Neural ensemble coding of satiety states. Neuron 51, 483-494. doi: 10.1016/j.neuron.2006.07.009

Elias, C. F., Aschkenasi, C., Lee, C., Kelly, J., Ahima, R. S., Bjorbæk, C., et al. (1999). Leptin differentially regulates NPY and POMC neurons projecting to the lateral hypothalamic area. Neuron 23, 775-786. doi: 10.1016/S0896-6273(01)8 0035-0
DFG within the Collaborative Research Center (SFB) 1134 (to VG), the National Natural Science Foundation of China (No. 81271490), and the Basic Research Project of Shanghai Science and Technology Commission (No. 14JC1401800, 15JC1400102).

\section{SUPPLEMENTARY MATERIAL}

The Supplementary Material for this article can be found online at: http://journal.frontiersin.org/article/10.3389/fnbeh. 2016.00091

Goforth, P. B., Leinninger, G. M., Patterson, C. M., Satin, L. S., and Myers, M. G. (2014). Leptin acts via lateral hypothalamic area neurotensin neurons to inhibit orexin neurons by multiple GABA-independent mechanisms. J. Neurosci. 34, 11405-11415. doi: 10.1523/JNEUROSCI.5167-13.2014

Grossman, S. P., Dacey, D., Halaris, A. E., Collier, T., and Routtenberg, A. (1978). Aphagia and adipsia after preferential destruction of nerve cell bodies in hypothalamus. Science 202, 537-539. doi: 10.1126/science.705344

Hassani, O. K., Henny, P., Lee, M. G., and Jones, B. E. (2010). GABAergic neurons intermingled with orexin and $\mathrm{MCH}$ neurons in the lateral hypothalamus discharge maximally during sleep. Eur. J. Neurosci. 32, 448-457. doi: 10.1111/j.1460-9568.2010.07295.x

Hassani, O. K., Lee, M. G., and Jones, B. E. (2009). Melanin-concentrating hormone neurons discharge in a reciprocal manner to orexin neurons across the sleep-wake cycle. Proc. Natl. Acad. Sci. U.S.A. 106, 2418-2422. doi: 10.1073/pnas.0811400106

Haynes, A. C., Jackson, B., Overend, P., Buckingham, R. E., Wilson, S., Tadayyon, M., et al. (1999). Effects of single and chronic intracerebroventricular administration of the orexins on feeding in the rat. Peptides 20,1099-1105. doi: 10.1016/S0196-9781(99)00105-9

Hoebel, B. G., and Teitelbaum, P. (1962). Hypothalamic control of feeding and self-stimulation. Science 135, 375-377. doi: 10.1126/science.135. 3501.375

Ison, M. J., Mormann, F., Cerf, M., Koch, C., Fried, I., and Quiroga, R. Q. (2011). Selectivity of pyramidal cells and interneurons in the human medial temporal lobe. J. Neurophysiol. 106, 1713-1721. doi: 10.1152/jn.00576.2010

Jennings, J. H., Ung, R. L., Resendez, S. L., Stamatakis, A. M., Taylor, J. G., Huang, J., et al. (2015). Visualizing hypothalamic network dynamics for appetitive and consummatory behaviors. Cell 160, 516-527. doi: 10.1016/j.cell.2014.1 2.026

Karnani, M. M., Szabó, G., Erdélyi, F., and Burdakov, D. (2013). Lateral hypothalamic GAD65 neurons are spontaneously firing and distinct from orexin-and melanin-concentrating hormone neurons. J. Physiol. 591, 933-953. doi: 10.1113/jphysiol.2012.243493

Kempadoo, K. A., Tourino, C., Cho, S. L., Magnani, F., Leinninger, G.-M., Stuber, G. D., et al. (2013). Hypothalamic neurotensin projections promote reward by enhancing glutamate transmission in the VTA. J. Neurosci. 33, 7618-7626. doi: 10.1523/JNEUROSCI.2588-12.2013

Kong, D., Vong, L., Parton, L. E., Ye, C., Tong, Q., Hu, X., et al. (2010). Glucose stimulation of hypothalamic MCH neurons involves $\mathrm{K}$ ATP channels, is modulated by UCP2, and regulates peripheral glucose homeostasis. Cell Metab. 12, 545-552. doi: 10.1016/j.cmet.2010.09.013

Leinninger, G. M., Opland, D. M., Jo, Y.-H., Faouzi, M., Christensen, L., Cappellucci, L. A., et al. (2011). Leptin action via neurotensin neurons controls orexin, the mesolimbic dopamine system and energy balance. Cell Metab. 14, 313-323. doi: 10.1016/j.cmet.2011.06.016

Lin, L., Chen, G., Xie, K., Zaia, K. A., Zhang, S., and Tsien, J. Z. (2006). Large-scale neural ensemble recording in the brains of freely behaving mice. J. Neurosci. Methods 155, 28-38. doi: 10.1016/j.jneumeth.2005. 12.032

Margules, D., and Olds, J. (1962). Identical "feeding" and "rewarding" systems in the lateral hypothalamus of rats. Science 135, 374-375. doi: $10.1126 /$ science. 135.3501 .374 
Marsh, D. J., Weingarth, D. T., Novi, D. E., Chen, H. Y., Trumbauer, M. E., Chen, A. S., et al. (2002). Melanin-concentrating hormone 1 receptordeficient mice are lean, hyperactive, and hyperphagic and have altered metabolism. Proc. Natl. Acad. Sci. U.S.A. 99, 3240-3245. doi: 10.1073/pnas.0527 06899

McGregor, R., Wu, M.-F., Barber, G., Ramanathan, L., and Siegel, J. M. (2011). Highly specific role of hypocretin (orexin) neurons: differential activation as a function of diurnal phase, operant reinforcement versus operant avoidance and light level. J. Neurosci. 31, 15455-15467. doi: 10.1523/JNEUROSCI.401711.2011

Mieda, M., Williams, S. C., Sinton, C. M., Richardson, J. A., Sakurai, T., and Yanagisawa, M. (2004). Orexin neurons function in an efferent pathway of a food-entrainable circadian oscillator in eliciting food-anticipatory activity and wakefulness. J. Neurosci. 24, 10493-10501. doi: 10.1523/JNEUROSCI.317104.2004

Mileykovskiy, B. Y., Kiyashchenko, L. I., and Siegel, J. M. (2005). Behavioral correlates of activity in identified hypocretin/orexin neurons. Neuron 46, 787-798. doi: 10.1016/j.neuron.2005.04.035

Muroya, S., Uramura, K., Sakurai, T., Takigawa, M., and Yada, T. (2001). Lowering glucose concentrations increases cytosolic $\mathrm{Ca} 2+$ in orexin neurons of the rat lateral hypothalamus. Neurosci. Lett. 309, 165-168. doi: 10.1016/S03043940(01)02053-5

Nakamura, K., Ono, T., and Tamura, R. (1987). Central sites involved in lateral hypothalamus conditioned neural responses to acoustic cues in the rat. $J$. Neurophysiol. 58, 1123-1148.

Nakamura, K., Ono, T., Tamura, R., Indo, M., Takashima, Y., and Kawasaki, M. (1989). Characteristics of rat lateral hypothalamic neuron responses to smell and taste in emotional behavior. Brain Res. 491, 15-32. doi: 10.1016/00068993(89)90084-X

Norgren, R. (1970). Gustatory responses in the hypothalamus. Brain Res. 21, 63-77. doi: 10.1016/0006-8993(70)90021-1

Ono, T., Nishino, H., Sasaki, K., Fukuda, M., and Muramoto, K.-I. (1981). Long-term lateral hypothalamic single unit analysis and feeding behavior in freely moving rats. Neurosci. Lett. 26, 79-83. doi: 10.1016/0304-3940(81)90 429-8

Oomura, Y., Ooyama, H., Sugimori, M., Nakamura, T., and Yamada, Y. (1974). Glucose inhibition of the glucose-sensitive neurone in the rat lateral hypothalamus. Nature 247, 284-286.

Peyrache, A., Lacroix, M. M., Petersen, P. C., and Buzsaki, G. (2015). Internally organized mechanisms of the head direction sense. Nat. Neurosci. 18, 569-575. doi: $10.1038 / \mathrm{nn} .3968$

Rosin, D. L., Weston, M. C., Sevigny, C. P., Stornetta, R. L., and Guyenet, P. G. (2003). Hypothalamic orexin (hypocretin) neurons express vesicular glutamate transporters VGLUT1 or VGLUT2. J. Comp. Neurol. 465, 593-603. doi: $10.1002 /$ cne. 10860

Rossi, M., Choi, S. J., O’shea, D., Miyoshi, T., Ghatei, M. A., and Bloom, S. R. (1997). Melanin-concentrating hormone acutely stimulates feeding, but chronic administration has no effect on body weight. Endocrinology 138, 351-355. doi: 10.1210/endo.138.1.4887

Sabatier, N., and Leng, G. (2008). Spontaneous discharge characteristic of neurons in the ventromedial nucleus of the rat hypothalamus in vivo. Eur. J. Neurosci. 28, 693-706. doi: 10.1111/j.1460-9568.2008.06389.x

Sakamaki, R., Uemoto, M., Inui, A., Asakawa, A., Ueno, N., Ishibashi, C., et al. (2005). Melanin-concentrating hormone enhances sucrose intake. Int. J. Mol. Med. 15, 1033-1039. doi: 10.3892/ijmm.15.6.1033

Sakurai, T., Amemiya, A., Ishii, M., Matsuzaki, I., Chemelli, R. M., Tanaka, H., et al. (1998). Orexins and orexin receptors: a family of hypothalamic neuropeptides and $\mathrm{G}$ protein-coupled receptors that regulate feeding behavior. Cell 92, 573-585. doi: 10.1016/S0092-8674(00)80949-6

Schwartzbaum, J. (1988). Electrophysiology of taste, feeding and reward in lateral hypothalamus of rabbit. Physiol. Behav. 44, 507-526. doi: 10.1016/00319384(88)90313-7

Serra, M., Pisu, M., Floris, I., and Biggio, G. (2005). Social isolation-induced changes in the hypothalamic-pituitary-adrenal axis in the rat. Stress 8, 259-264. doi: 10.1080/10253890500495244
Sheng, Z., Santiago, A. M., Thomas, M. P., and Routh, V. H. (2014). Metabolic regulation of lateral hypothalamic glucose-inhibited orexin neurons may influence midbrain reward neurocircuitry. Mol. Cell. Neurosci. 62, 30-41. doi: 10.1016/j.mcn.2014.08.001

Shimada, M., Tritos, N. A., Lowell, B. B., Flier, J. S., and Maratos-Flier, E. (1998). Mice lacking melanin-concentrating hormone are hypophagic and lean. Nature 396, 670-674. doi: 10.1038/25341

Shiraishi, T. (1988). Feeding related lateral hypothalamic neuron responses to odors depend on food deprivation in rats. Physiol. Behav. 44, 591-597. doi: 10.1016/0031-9384(88)90323-X

Singer, W., and Gray, C. M. (1995). Visual feature integration and the temporal correlation hypothesis. Annu. Rev. Neurosci. 18, 555-586. doi: 10.1146/annurev.ne.18.030195.003011

Skaggs, W. E., and McNaughton, B. L. (1996). Theta phase precession in hippocampal. Hippocampus 6, 149-172. doi: 10.1002/(SICI)10981063(1996)6:2<149::AID-HIPO6>3.0.CO;2-K

Stanley, B., Hoebel, B., and Leibowitz, S. (1983). Neurotensin: effects of hypothalamic and intravenous injections on eating and drinking in rats. Peptides 4, 493-500. doi: 10.1016/0196-9781(83)90054-2

Tabuchi, E., Yokawa, T., Mallick, H., Inubushi, T., Kondoh, T., Ono, T., et al. (2002). Spatio-temporal dynamics of brain activated regions during drinking behavior in rats. Brain Res. 951, 270-279. doi: 10.1016/S0006-8993(02) 03173-6

Torrealba, F., Yanagisawa, M., and Saper, C. (2003). Colocalization of orexin a and glutamate immunoreactivity in axon terminals in the tuberomammillary nucleus in rats. Neuroscience 119, 1033-1044. doi: 10.1016/S0306-4522(03)00238-0

Tsunada, J., Lee, J. H., and Cohen, Y. E. (2012). Differential representation of auditory categories between cell classes in primate auditory cortex. J. Physiol. 590, 3129-3139. doi: 10.1113/jphysiol.2012.232892

van den Pol, A. N., Acuna-Goycolea, C., Clark, K. R., and Ghosh, P. K. (2004). Physiological properties of hypothalamic MCH neurons identified with selective expression of reporter gene after recombinant virus infection. Neuron 42, 635-652. doi: 10.1016/S0896-6273(04)00251-X

Vaughn, A. W., Baumeister, A., Hawkins, H., and Anticich, T. G. (1990). Intranigral microinjection of neurotensin suppresses feeding in food deprived rats. Neuropharmacology 29, 957-960. doi: 10.1016/0028-3908(90) 90147-J

Vigneswaran, G., Kraskov, A., and Lemon, R. N. (2011). Large identified pyramidal cells in macaque motor and premotor cortex exhibit "thin spikes": implications for cell type classification. J. Neurosci. 31, 14235-14242. doi: 10.1523/JNEUROSCI.3142-11.2011

Yamamoto, T., Matsuo, R., Kiyomitsu, Y., and Kitamura, R. (1989). Response properties of lateral hypothalamic neurons during ingestive behavior with special reference to licking of various taste solutions. Brain Res. 481, 286-297. doi: 10.1016/0006-8993(89)90805-6

Yamanaka, A., Beuckmann, C. T., Willie, J. T., Hara, J., Tsujino, N., Mieda, M., et al. (2003). Hypothalamic orexin neurons regulate arousal according to energy balance in mice. Neuron 38, 701-713. doi: 10.1016/S0896-6273(03)00 331-3

Yamanaka, A., Sakurai, T., Katsumoto, T., Yanagisawa, M., and Goto, K. (1999). Chronic intracerebroventricular administration of orexin-A to rats increases food intake in daytime, but has no effect on body weight. Brain Res. 849, 248-252. doi: 10.1016/S0006-8993(99)01905-8

Conflict of Interest Statement: The authors declare that the research was conducted in the absence of any commercial or financial relationships that could be construed as a potential conflict of interest.

Copyright (C) 2016 Tang, Benusiglio, Grinevich and Lin. This is an open-access article distributed under the terms of the Creative Commons Attribution License (CC BY). The use, distribution or reproduction in other forums is permitted, provided the original author(s) or licensor are credited and that the original publication in this journal is cited, in accordance with accepted academic practice. No use, distribution or reproduction is permitted which does not comply with these terms. 